\title{
Population Mobility and Adaptive Human Behaviour as Disease Control Mechanisms
}

\author{
Baltazar Espinoza Cortes* \\ Biocomplexity Institute \& Initiative, University of Virginia, Charlottesville, VA, USA \\ ${ }^{\star}$ Corresponding author: Baltazar Espinoza Cortes, Biocomplexity Institute \& Initiative, University of Virginia, Charlottesville, VA, USA; Tel: 852872402
}

Received: July 23, 2020; Accepted: July 27, 2020; Published: July 30, 2020

The control of emergent infectious diseases has historically been a complex problem posing challenges on many different fronts. The absence of a vaccine or treatment forces us to rely on non-pharmaceutical interventions i.e., social distancing and mobility restrictions. Most countries' first response to the ongoing Covid-19 pandemic has been to implement travel restrictions and social distancing policies. However, previous outbreaks have shown that the efficiency of these control measures varies.

The problem of deciding when, where and how to implement such control measures has multiple dimensions. Their effectiveness may also be evaluated by different criteria, depending on the intended goal. The spatial-temporal scales at which these interventions are implemented, the socio-economic and age distribution of the affected population, and the connectivity of the population with neighboring regions are amongst the factors to consider when assessing their effectiveness.

Recently, extreme mobility restrictions (cordon sanitaires) have been imposed in two very different regions, with contrasting results. On one hand, the cordon sanitaire imposed during the 2014 West African Ebola outbreak, may have increased the rate of transmission within the cordoned region [1,2]. On the other hand, the cordon sanitaire implemented along with the social distancing measures in Wuhan, seems to have reduced the number of Covid-19 cases and delayed its spread within the city and China [3,4]. The effectiveness of these interventions was driven by the population-specific characteristics in which the control measures were imposed.

Mathematical models analyzing disease dynamics in regions comprising populations exhibiting dramatic disparities may help to disentangle the role of local characteristics on the efficiency of control measures. Specifically, the effectiveness of mobility restrictions within and between heterogeneous but locally connected communities has been measured in terms of the final number of infected individuals [5]. It has been shown that it is possible to find conditions under which mobility across community's results in a reduced number of infected individuals compared to the isolation of communities through cordon sanitaria's [6].

Classic mathematical models assume a single health authority controlling interactions between sub-populations. In this approach, the overall mixing structure is modified at the scale at which the health authority operates. However, an emerging class of models addresses the effect of decentralized interpersonal contact decisions on disease dynamics [7-9]. These models focus on the economics of contact decisions at the individual scale to analyze the feedback between the cost of disease, the risk of infection during an epidemic, and disease dynamics.

The key step in framing the lessons learned from these modeling approaches (operating at different scales) for public health policy model was captured, in broad sense, by Simon Levin in his address as the 2004 recipient of the Heineken award: "Understanding the links between individual behavior and societal consequences, and characterizing the networks of interaction and influence, create the potential to change the reward structures so that the social costs of individual actions are brought down to the level of individual payoffs".

\section{References}

1. Espinoza B, Moreno V, Bichara D, Castillo-Chavez C (2016) Assessing the efficiency of movement restriction as a control strategy of ebola. Mathematical and Statistical Modeling for Emerging and Re-emerging Infectious Diseases 123-145.

2. Towers S, Patterson-Lomba, O, Castillo-Chavez C (2014) Temporal variations in the effective reproduction number of the 2014 West Africa Ebola outbreak. PLoS Currents 18: 6. [crossref]

3. Tian H, Liu Y, Li Y, Wu CH, Chen B, et al. (2020) An investigation of transmission control measures during the first 50 days of the COVID-19 epidemic in China. Science 368: 638-642.

4. Lau H, Khosrawipour V, Kocbach P, Mikolajczyk A, Schubert J, et al. (2020) The positive impact of lockdown in Wuhan on containing the COVID-19 outbreak in China. Journal of Travel Medicine 27: 37. [crossref]

5. Espinoza B, Moreno V, Bichara D, Castillo-Chavez C (2016) Assessing the efficiency of movement restriction as a control strategy of ebola. In Mathematical and Statistical Modeling for Emerging and Re-emerging Infectious Diseases 123-145.

6. Espinoza B, Castillo-Chavez C, Perrings C (2020) Mobility restrictions for the control of epidemics: When do they work?. PLoS One 15: 0235731. [crossref]

7. Castillo-Chavez C, Bichara D, Morin BR (2016) Perspectives on the role of mobility, behavior, and time scales in the spread of diseases. Proceedings of the National Academy of Sciences 113: 14582-14588. [crossref]

8. Perrings C, Castillo-Chavez C, Chowell G, Daszak P, Fenichel EP, et al. (2014) Merging economics and epidemiology to improve the prediction and management of infectious disease. EcoHealth 11: 464-475. [crossref]

9. Fenichel EP, Castillo-Chavez C, Ceddia MG, Chowell, G, Parra PAG, et al. (2011) Adaptive human behavior in epidemiological models. Proceedings of the National Academy of Sciences 108: 6306-6311. 